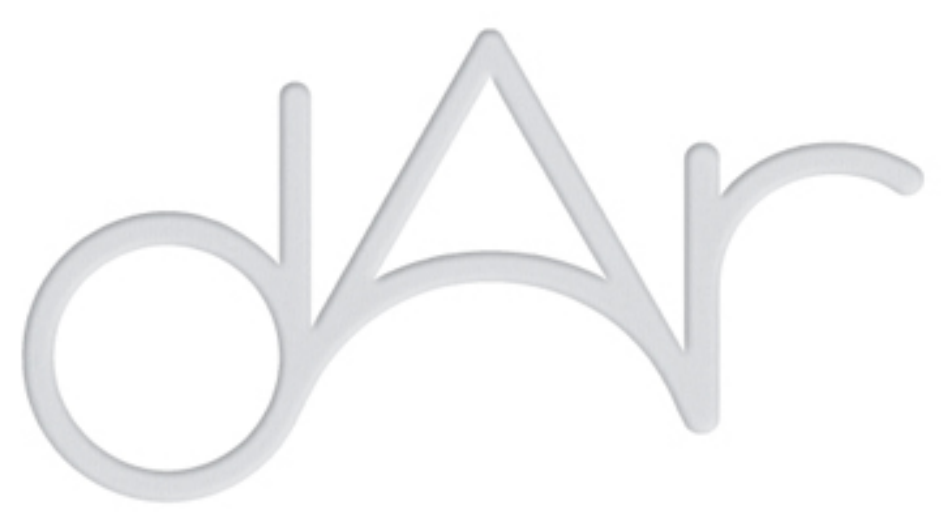

Os corpos na escultura do século XVI
Autor(es): $\quad$ Gonçalves, Carla Alexandra
Publicado por: Centro de Estudos em Arqueologia, Artes e Ciências do Património
URL persistente:
URI:http://hdl.handle.net/10316.2/39299
DOI:
DOI:http://dx.doi.org/10.14195/2182-844X_2_4

Accessed : $\quad$ 26-Apr-2023 02:45:16

A navegação consulta e descarregamento dos títulos inseridos nas Bibliotecas Digitais UC Digitalis, UC Pombalina e UC Impactum, pressupõem a aceitação plena e sem reservas dos Termos e Condições de Uso destas Bibliotecas Digitais, disponíveis em https://digitalis.uc.pt/pt-pt/termos.

Conforme exposto nos referidos Termos e Condições de Uso, o descarregamento de títulos de acesso restrito requer uma licença válida de autorização devendo o utilizador aceder ao(s) documento(s) a partir de um endereço de IP da instituição detentora da supramencionada licença.

Ao utilizador é apenas permitido o descarregamento para uso pessoal, pelo que o emprego do(s) título(s) descarregado(s) para outro fim, designadamente comercial, carece de autorização do respetivo autor ou editor da obra.

Na medida em que todas as obras da UC Digitalis se encontram protegidas pelo Código do Direito de Autor e Direitos Conexos e demais legislação aplicável, toda a cópia, parcial ou total, deste documento, nos casos em que é legalmente admitida, deverá conter ou fazer-se acompanhar por este aviso.

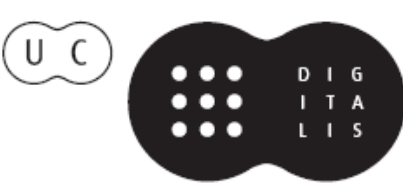




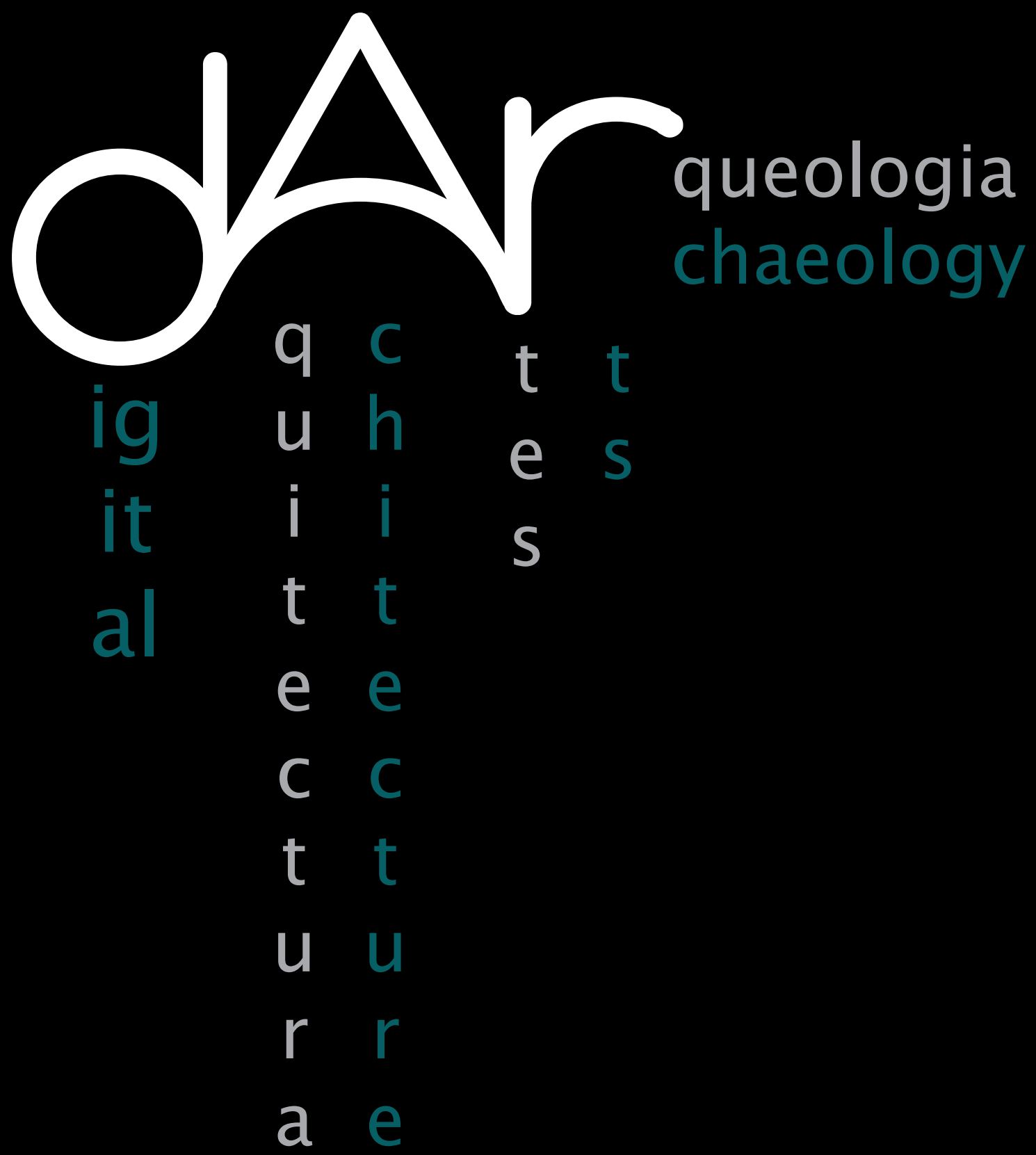




\title{
OS CORPOS NA ESCULTURA DO SÉCULO XVI
}

\author{
Carla Alexandra Gonçalves* \\ Universidade Aberta \\ CEAACP - Centro de Estudos em Arqueologia, \\ Artes e Ciências do Património
}

\section{RESUMO}

Estabelecemos, como objecto de trabalho para este workshop, um problema metodológico: como estudar o corpo na escultura do século XVI. Para responder a esta interrogação de cariz processual partamos de um conjunto de perguntas que abrem caminho para a determinação de hipóteses de trabalho que nos importam, e às quais tentaremos, depois desta exposição, responder: a) Haverá um corpo para a ldade Moderna? Havendo, que corpo será esse (mundial, europeu, peninsular, português)? b) A representação do corpo durante a Idade Moderna espelha o que o Homem vê, ou o que o Homem quer ver? c) A representação do corpo na ldade Moderna espelha a realidade ou a utopia? Trata-se, efectivamente, de um corpo-realidade ou de um corpo-ficção? d) O que diz o corpo (mãos, rostos, poses, expressão corporal, gestualidade) na escultura do século XVI? e) Antevê-se algum género de manipulação artística do corpo ao serviço da conjuntura epocal? f) A escultura consubstancia uma boa fonte documental para aferir sobre o que é o corpo para cada momento histórico? g) A pergunta que inicia este conjunto de reflexões é a mesma que encerra este elenco geral: o que me diz o teu corpo?

Palavras-chave: o corpo através da imagem; a anatomia no século XVI.

\begin{abstract}
The main theme of this workshop lies on a methodological problem: how can someone study the body in the sculpture of the XVIth century? To answer this question, it is required to ask some other questions, in order to select several relevant working hypotheses: a) Is there a body in the modern era? And, if we agree that there is indeed, what kind of body is it? Is it a universal, or a European, or a Peninsular or a Portuguese kind of body? b) During the modern era, does the body representation reflect what mankind sees, or does it reflect what mankind wants to see? c) During the modern era, does the body representation reflect reality or utopia? Is it a real body or is it a fictional one? d) In the sculpture of the XVIth century, what does the body tell us (i.e., its hands, its faces, its attitudes, its body expressions, its gestures)? e) Can it be detected some kind of artistic manipulation of the body, as a consequence of the historical period in which its representation emerges? f) Is sculpture a good documentary resource to assess how the body is visualized in each historical period? $\mathrm{g}$ ) Finally, the question that introduces these reflections is, after all, the same that may well conclude them: what does your body tell me?para cada momento histórico? g) A pergunta que inicia este conjunto de reflexões é a mesma que encerra este elenco geral: o que me diz o teu corpo?
\end{abstract}

Keywords: the body through the image; anatomy in the sixteenth century. 
Quando examinamos a escultura moderna (entre outras possibilidades cronológicas) estamos, de facto, a estudar corpos ou as suas representações. Raras vezes nos deparamos com outras formas que não as dos corpos, reais ou irreais, assumidos ou dissolvidos nos temários que os cingem e aos quais dão corpo, íntegros ou fragmentários, mas todos eles falantes. Por este motivo é o corpo uma realidade densamente presente no horizonte artístico e, especificamente, no horizonte da investigação em escultura.

Na realidade, tencionamos hoje, e ainda, discernir o corpo (na realidade tencionamos hoje, e ainda, discernir o Homem). E neste desbravamento procuramos saber o que ele nos diz, como ele é reconhecido, como é visto esse organismo que nos consubstancia e que nos faz pertencer ao mundo material. A nossa ligação com o mundo faz-se através do nosso corpo animado, ou vivo. Estudar o que nos diz o corpo através de um documento especial que é a escultura, realidade objectiva e tridimensional, com volume e textura que activam a permeabilidade e a empatia, realidade tangível e narrativa, discursiva e afável, palpável, e de leitura quase instantânea, é, afinal, uma actividade que nos parece muito simples. Afinal somos todos corpos que se afrontam - podemos pensar.

Mas no confronto com a escultura nada podemos adivinhar senão o que cada peça nos quer dizer na sua individualidade, ou seja, o que ela nos diz sobre a sua própria representação, ou sobre o assunto que ela dita, ou sobre a forma que ela assume para dizer-se. Na verdade, estudar o corpo na escultura do século XVI envolve que estudemos, para além dela, outras fontes de averiguação que, conjuntamente, enformarão um agrupado mais amplo com o qual nos debatemos. Por outras palavras, para empreender um trilho de investigação acertado (ou menos errado) nestas matérias temos de realizar trabalho transdocumental, ou seja, temos de servir-nos da escultura (como princípio e como fim), mas também de outras progénies físicas, gráficas e iconográficas que nos permitam exalçar pequenas, muito pequenas ideias sobre este complexo problema que, ainda assim, nos parece sempre ser tão familiar.

Por esta via, a escultura (bem como o relevo e a arte integrada) constitui-se como um fragmento de um caso amplo, onde se entrecruzam sinais que devemos tentar fazer reanimar, para juntar e (re) criar esta imagem que nos importa fazer viver: a realidade do homem enquanto ser objectivo e integrado num espaço mais alargado onde habita, onde interfere, ou onde vive, onde ama, onde repudia, onde teme e onde acaba por perecer. Só realizando um denso trabalho transdisciplinar que nos permita, de forma totalizada, entender o que nos dizem todos os corpos, podemos estabelecer padrões de pensamento (mais ou menos achegados à verdade, sabendo embora da sua enorme dificuldade) que nos conduzam à inteligibilidade mais geral sobre o caso, intentando atingir ideias tão globais quanto nos for possivel (sempre sujeitas aos seus devidos testes de fiabilidade), já que nos situamos no âmbito das ciências humanas e sociais. Só mediante os processos, conhecidos, de cruzamento de fontes e de saberes podemos, com alguma persistência, realizar o nosso objectivo maior que é o entendimento do homem nas suas tantas dimensões: enquanto corpo singular, corpo comportamental, corpo social, corpo político, corpo religioso, corpo quotidiano, corpo simbólico e alegórico, corpo humano e corpo utópico.

De entre as tantas possibilidades de cruzamento de ideias e de fontes possíveis para ajudar-nos a entender o corpo esculpido durante o século XVI escolhemos uma que nos parece muito útil, no contexto deste workshop que almeja provocar os presentes e estabelecer compromissos de interactividade e de reflexão: a anatomia do século XVI.

Na realidade, este caminho de reflexão não nos foi difícil de estabelecer, já que o estudo da anatomia prende-se, de perto, com o trabalho artístico, porque o conhecimento anatómico determina a eficácia do discurso artístico, porque o 
artista compromete-se, de perto, com os resultados da actualidade dos estudos em anatomia, porque o artista recorre (e empreende) ao estudo anatómico, porque a anatomia enforma o desenho e vive a par com ele, porque o desenvolvimento artístico liga-se sobremaneira, à cultura anatómica de cada época e porque o anatomista consubstancia um género de artista muito singular.

Explicou-nos Giorgio Vasari, em 1550, que à escultura é necessário que tenha as proporções perfeitas, bem como as poses, o desenho, a união, a graça e a diligência de execução para que todo o conjunto possa demonstrar o engenho e o valor do artista. Já sobre o desenho, Vasari ensinava que não poderia ter um bom princípio caso não tivessem sido feitos estudos do natural, e de estátuas e de relevos antigos. Mas o melhor estudo para o desenho é o da nudez de homens e de mulheres vivos, retendose na memória os músculos do torso, da coluna, as pernas, os braços, os joelhos e o esqueleto, de modo tal que, não tendo os modelos diante do olhar se possam formar as figuras através da imaginação e em qualquer pose. Mas também é necessário terem-se visto cadáveres dissecados para ter-se uma ideia do esqueleto, dos músculos, dos nervos e de tudo quanto se refere à anatomia para poder assim, com conhecimento e segurança, colocar os membros e os músculos das figuras que vão desenhar-se. Os que têm este conhecimento realizam com perfeição os contornos das figuras e demonstram boa graça e belo estilo.?

\section{A anatomia no século $X V I$}

Sabemos que para entender a produção artística de uma determinada época temos de conhecer a conjuntura cultural e científica (para além de outras) que lhe subjaz. Da mesma maneira, para o estudo da anatomia do século XVI, é imprescindível que conheçamos a realidade cultural e mental anterior a este momento histórico, também porque a história decorre e porque os acontecimentos vão determinando outros tantos, numa cadeia de sucessões que consubstanciam continuidades.
Para isso, e para não recuarmos mais tempo, situemo-nos no humanismo de Chartres do século XII. Tratou-se de um humanismo verdadeiro, na medida em que aquele pensamento foi buscar as suas fontes aos Antigos, e porque o homem era já visto como o centro da ciência, da teologia e da filosofia. Na perspectiva de que o homem une a fé e a razão, os pensadores de então também se interessaram pelos animais, os reversos do homem: «A antítese animal-homem é uma das grandes metáforas deste século. No bestiário românico, nesse mundo grotesco trazido do Oriente e que o imaginário popular reproduz pelo seu simbolismo, o mundo escolar vê um humanismo às avessas - e dele se afastará, aliás, para inspirar aos escultores góticos um modelo novo: o homem.». ${ }^{3}$

É durante o século XII que se reinaugura o estudo da anatomia (Antiga) e da fisiologia humana: ao homem é-lhe restituído o corpo. O corpo surge como uma estrutura bela e harmónica, concebida por Deus como o centro do mundo. Deus criou o mundo para o homem, dotando-o de razão para, com ela, conhecer e agir na natureza. O mundo transforma-se num gigante estaleiro que o cientista e o artesão transformam e (re)criam, cooperando com Deus e com a natureza e completando a Criação. Toda a obra (diz Guilherme de Conches) é obra do Criador, obra da natureza ou do homem-artesão que imita a natureza.

Tomás de Aquino defendia, no século XIII, que um homem é belo quando os seus membros mantêm uma proporção decente no que se refere à quantidade e posição, e quando a sua cor é clara e nítida. Consequentemente, em relação às demais coisas deve-se conceber, proporcionalmente, que algo é belo quando possui a claridade própria de seu género, espiritual ou corporal, e quando está constituído conforme uma proporção devida. ${ }^{4}$

Expressa este agrupado de ideias a obra do desenhador, gravador e filósofo (e visionário) italiano Opicinus de Canistris 
(1296 - c. 1354), , conhecido também como Anonymous Ticinensis, que nos deixou um conjunto vasto e complexo de diagramas cosmológicos e, de entre eles, refiramos o Diagrama com a Crucificação ${ }^{6}$ que nos oferece um combinado de imagens e de texto que remete para o diagrama da (recente) Igreja. A (incorruptível) Igreja é referida através da imagem de uma figura humana aureolada que possui, no seu interior (corpo) um círculo onde se desenha Cristo Crucificado, ladeado pela Virgem e por S. João. O desenho alude explícita, ou implicitamente, ao conjunto de corpos que enformam a Igreja Universal e as suas conexões com a estrutura cósmica. É particularmente relevante o uso da métrica corporal para consubstanciar a realidade deste diagrama.

Do mesmo autor, conhece-se o colorido Diagrama com os símbolos do Zodíaco, ${ }^{7}$ temário tão relevante durante a ldade Média (tal como o Homem Zodiacal). Este intrincado diagrama inclui vários desenhos (nem sempre fáceis de explicar) e, de entre eles, contam-se os símbolos do zodíaco, os Doutores da Igreja, a genealogia da Virgem, as Ordens monásticas, os meses do ano, os dias, o mapa mundi, as personificações da Igreja, os Evangelistas, os Apóstolos, os quatro tipos da exegese bíblica, etc. O diagrama conforma, claramente, a união entre as realidades cósmica, terreal e corporal, já que é o corpo humano que suporta todo o discurso e é essa realidade que nos importa.

Anos mais tarde, em 1487, Leonardo da Vinci retoma o homo quadratus medieval, o homo imago mundi, o homem na roda (a relação profícua entre o micro e o macrocosmos) que a visionária beneditina Saint Hildegard (1098 - 1179) havia desenhado amiúde no seu Liber divinorum operum [ms. Biblioteca da Universidade, Gand, Cod. 241, 1170-1171]. É interessante verificar que a ideia quatrocentista do homo quadratus não é nova, e que as conspecções onzecentistas (apesar de terem gerado uma fortuna menor) de Hildegard possuem uma enorme relevância nesta conjuntura intelectual que se expande no tempo continuamente.
O homem do século XV é a medida de todas as coisas e o seu corpo funcional, proporcionado, claro, harmónico e belo, traduz a realidade da natureza e do mundo que com ele emparceira como um outro corpo, dilatado e preenchido. O corpo é, como se vê, a entidade que rege a materialidade, situando-se entre o terreno e o extra-corpo místico, entre o céu e a terra, e é pertença do homem que o usa, também como um meio de manifestar as coisas da alma.

Os desenhos de Leonardo da Vinci, particularmente os esboços do corpo e da sua anatomia realizados nos alvores do século XVI, traduzem uma preocupação real com o conhecimento do homem, com o seu funcionamento e tecnologia, bem como com a sua realidade física, objectiva e materializável. Como sabemos, o corpo como o centro de um conjunto de preocupações ligadas à ciência e à arte vai ganhando um terreno particularmente fértil durante esta centúria.

O cirurgião e farmacologista alemão

Hieronymus Brunschwig (1450 - 1512)

constitui-se como um importante anatomista do século XVI. No seu Liber de arte distillandi de compositis [Estrasburgo: Johann Grüninger, 1512], 8 o primeiro tratado de cirurgia publicado na Alemanha, o autor desenha e revela um agrupado de assuntos relacionados com a química e com a farmacologia, ensina os métodos de destilação de extractos de plantas e animais, descreve algumas plantas medicinais e lista algumas doenças fazendo corresponder-lhes algumas plantas e ervas medicinais. O que nos importa neste livro é, fundamentalmente, a forma como o autor desenha o corpo humano que serve de apoio à literatura. Hieronymus Brunschwig grava o corpo físico, por vezes aberto para deixar ver as entranhas que competem ao desenvolvimento dos temas tratados, de uma forma bela, rigorosa e fruível, um corpo humano do primeiro Renascimento que recorda os gravados de Martin Schongaver (entre outros).

Jacopo Berengario da Carpi (ou lacopo Barigazzi, Maestro lacomo da Carpi ou 
Jacobus Berengarius Carpensis, C. 1460 c. 1530) foi um importante físico italiano, médico de Lorenzo de Medici e do Duque de Urbino (1517), entre outras figuras proeminentes do seu lugar e tempo. Filho de um barbeiro-cirurgião que o introduziu no ofício, Berengario graduou-se, em 1489, na renomada Universidade de Bolonha (onde leccionou entre 1502 e 1527) e, depois disso, aprendeu a gravar com o gravador e tipógrafo humanista Aldo Manuzio (Aldus Manutius, o célebre gravador da Hypnerotomachia Poliphili de Francesco Colonna, através da sua tipografia Aldine, em 1499).

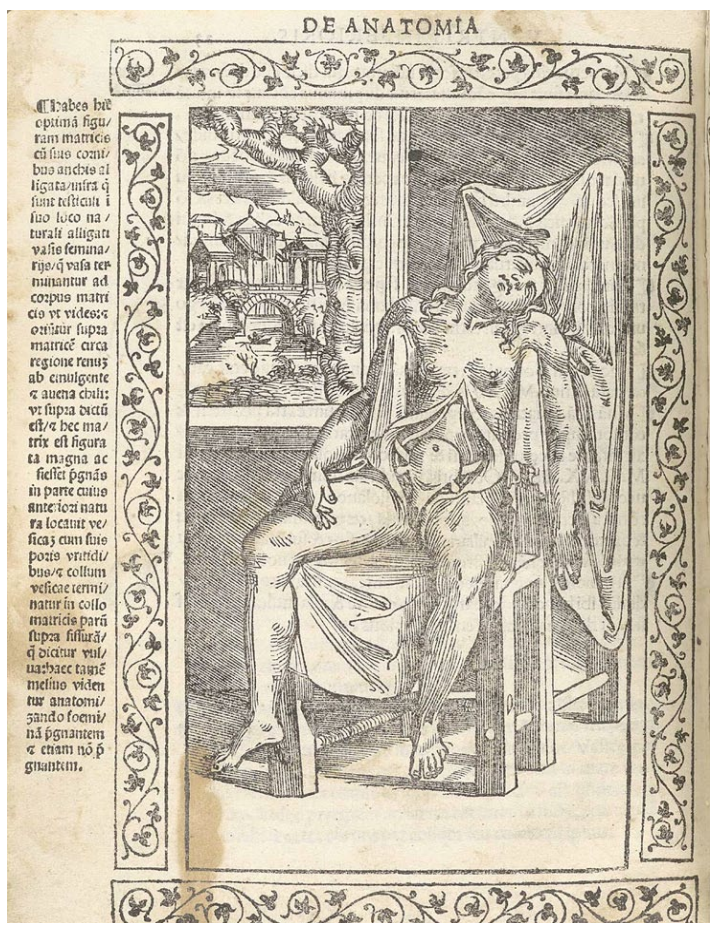

Fig.1 - Jacopo Berengario da Carpi, (desenhos de Hugo da Carpi).

Isagogae breves, perlucid[a]e acuberrim[a] $\mathrm{e}$, in anatomia $[\mathrm{m}]$ humani corporis a co[m]muni medicoru[m] academia usitata[m]. Impressum \& nouiter reuissum Bononi[a]e: Per Benedictum Hectoris bibliopolam Bononiensem, anno uirginei partus 1523 sub die xv. Iulii, f. 23 v. ${ }^{\circ}$

Berengario tornou-se conhecido como um dos primeiros anatomistas do Renascimento, defendendo que a observação consiste na mais importante das actividades na construção do conhecimento anatómico. ${ }^{9}$ Berengario foi criticado pelos seus pares porque julgavam que o cientista dissecava corpos ainda vivos, tal era a densidade do seu trabalho. Na sua famosa obra Isagogae breves, perlucidae ac uberrimae in anatomiam humani corporis [Bologna: Beneditcus Hector, 1523] o anatomista divulga um grupo de gravuras interessantíssimas, ${ }^{10}$ devidamente acompanhadas pela legenda que as explica atendendo aos objectivos do livro. Desta feita, as imagens que ilustram o texto acabam por revelar-se, para nós, mais importantes do que a redacção, ocupando a grande parte dos fólia do Livro (figs. 1 e 2) que intenta descrever, de forma detalhada

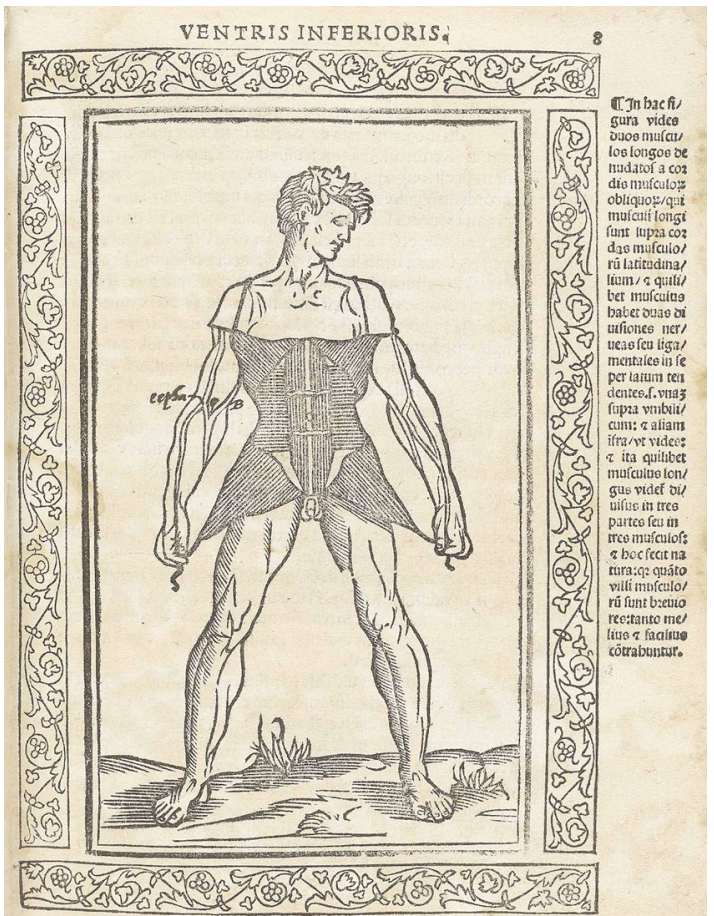

Fig.2 - Jacopo Berengario da Carpi (desenhos de Hugo da Carpi),

Isagogae breves, perlucid[a]e acuberrim[a] $\mathrm{e}$, in anatomia[m] humani corporis a co[m]muni medicoru[m] academia usitata $[\mathrm{m}]$..., fl. 9 v. ${ }^{\circ}$

e concisa, a anatomia do corpo humano, e servir como um manual de dissecação.

O tratado De humani corporis fabrica libri septem (em português, A fábrica do corpo humano em sete livros), do belga Andreas Vesalius (1514 - 1564) publicou-se 
em 1543 e constituiu-se como a primeira, e uma das mais relevantes fontes de conhecimento anatómico para o século $X V I$, estabelecendo a duradoura parceria entre a ciência anatómica e o trabalho artístico.

Andreas Vesalius descendia de uma família de físicos e de farmacologistas e, por isso, estudou na Universidade de Lovaina, mais tarde em Pádua, o maior centro de estudos anatómicos da Europa de então, onde Ihe foi oferecida a cátedra de cirurgia e anatomia (1537). Foi médico do Imperador Carlos $\vee$ e de Filipe II de Espanha no meado do século XVI.

Acreditando não ser possível ser-se um físico-cirurgião sem conhecimentos anatómicos, Vesalius realizava dissecações que os alunos desenhavam durante as lições. $O$ interesse pelas suas aulas fez com que o governo de Pádua lhe oferecesse os cadáveres dos criminosos para trabalhar e foi desta forma que a dissecação de cadáveres passou a consubstanciar-se como uma prática pedagógica de grande fortuna. A portada da segunda edição do tratado de Andreas Vesalius ${ }^{11}$ apresenta o teatro anatómico, ${ }^{12}$ desenho que é considerado como o primeiro registo de um acontecimento como este em ambiente de sala de aula e que criou as esteiras que conhecemos.

Os livros do Tratado de Vesalius foram ilustrados com os desenhos realizados pelo seu conhecido colaborador flamengo Jan Stephan van Calcar (ou Johannes Stephanus van Calcar, ou Giovanni da Calcar, 1499-1546), ${ }^{13}$ célebre pupilo de Ticiano (1536-37), e gravados em Veneza por Francesco Marcolini (1505-1560). ${ }^{14}$ Estes excepcionais desenhos ofereceram aos artistas do segundo meado do século XVI um importante reportório de imagens, retratando e explicando o corpo humano desde o interior, com os seus vários ossos, órgãos, músculos, a superfície e o funcionamento da pele... As figuras apresentam belíssimos e rigorosos escorços, ou o corpo humano nas suas várias posições, facilitando o entendimento dos movimentos, na relação com o funcionamento dos músculos que se alteram na medida da gestualidade.

O leonês Juan Valverde (1525 - 1588) foi outro importante anatomista do século XVI. Estudou anatomia em Pádua com Realdus

Columbo (1515-1559) e trabalhou com Bartholomew Eustachio (1500-1574) em Roma. Ficou conhecido com a sua obra Historia de la composición del cuerpo humano [Roma: Antonio Salamanca, y Antonio Lafrerii, 1556], ${ }^{15}$ que inclui reproduções de gravuras de Vesalius (facto que lhe valeu desaprovações) e originais de Gaspar Becerra e de Nicolas Beatrizet. Este livro foi durante criticado da altura, acusando-se o autor de não ter dissecado o suficiente para realizar o seu trabalho, e na medida em que usou, para ilustrar o livro, alguns desenhos extravagantes, como as armaduras romanas contendo órgãos internos (numa alusão à violência dos ferimentos em batalha), ou homens a descarnar-se. Destacamos, nesta obra, a Tauola I do Livro II, a fl. 64 (fig. 3), que representa o corpo de um homem despido da sua pele que empunha na mão direita e que nos recorda muitíssimo a imagem da pele de São Bartolomeu (ou do próprio autor) que Miguel Ângelo pintou no Juízo Final da Capela Sistina entre 1531-42.

Depois de Vesalius surgem outros anatomistas que desenvolveram os seus trabalhos sob a sua influência e que, por sua vez, exerceram grande dominação no panorama da ciência e da arte dos séculos XVI e XVII, particularmente os estudos e desenhos de Hieronymus Fabricius e, depois deles, os trabalhos dos seus dilectos discípulos Julius Casserius e Adriaan van den Spiegel.

O anatomista italiano Girolamo Fabrici (ou Hieronymus Fabricius, 1533 - 1619) foi o grande sucessor de Vesalius em Pádua, onde também ensinou anatomia e cirurgia. O seu trabalho destacou-se no âmbito da anatomia comparada, da cirurgia, fisiologia e, particularmente, da embriologia. Dedicou-se ao estudo detalhado do sistema circulatório e investigou um sem número de doenças, exercendo a medicina e registando os resultados do seu trabalho 


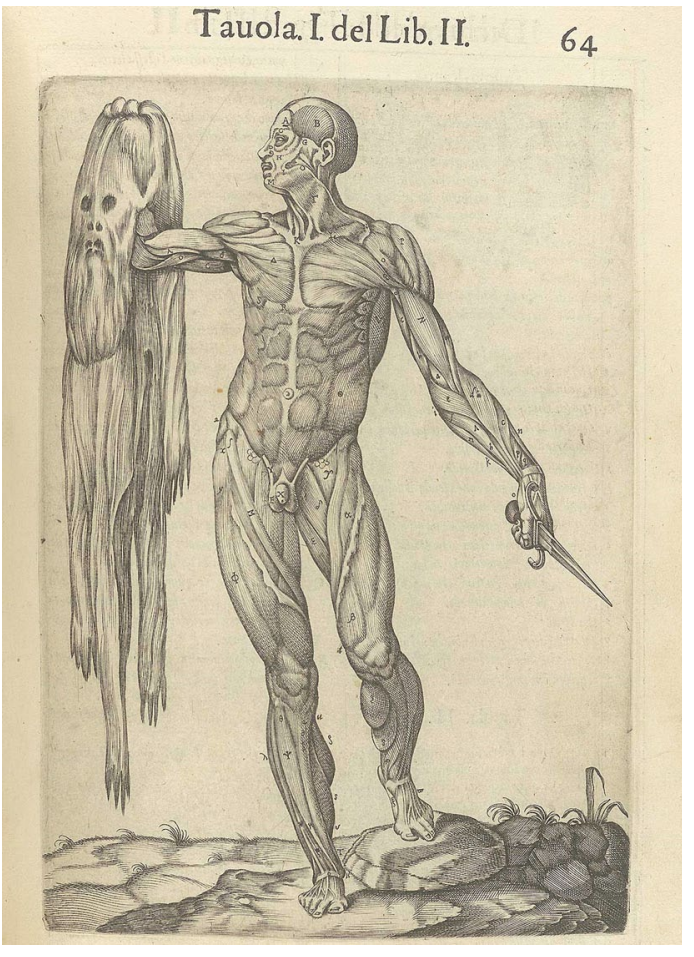

Fig.3 - Juan Valverde de Amusco, Historia de la composición del cuerpo humano . Roma: Ant. Salamanca \& Antonio Lafrery, 1556, Tuola I. Lib. II.

cf.:

http://bdh-rd.bne.es/viewer.vm?id=0000050806 ou

http://purl.pt/15007/3/\#/0

em diversos álbuns e tratados. A sua investigação ajudou a construir o Teatro Anatómico de Pádua, terminado em 1594 e baptizado com o seu nome. ${ }^{16}$

Um dos discípulos de Fabricius que agora nos importa foi o físico-cirurgião e anatomista Julius Casserius (1552-61 - 1616). Na sua obra De Vocis Auditusque Organis Historia Anatomica, \&c. Tractatibus duobus explicata, datada de entre 1600 e 1601 , encontramos um conjunto de gravuras valiosíssimo, especialmente as que se dedicam aos músculos do rosto e dos maxilares (fig. 4) que terão, sem sombra de dúvida, influenciado sobremaneira os artistas plásticos que necessitavam de encontrar informações detalhadas sobre o assunto e que não acediam directamente à prática da dissecação.
Destaquemos também outros dois discípulos de Fabricius: os anatomistas Giulio Casseri (ou Casserio, ca. 1552-1616) e Adriaan van den Spiegel (ou Spigelius, 1578-1625). Casseri, a par da investigação que foi desenvolvendo, do ofício enquanto médico e das lições, trabalhou num importante tratado sobre o corpo humano, obra que iniciou em 1600, mas que não chegou a termo antes do ano da sua morte. Por esse motivo, foi o físico-cirurgião formado em Lovaina, Adriaan van den Spiegel, que entretanto viria a trabalhar com Casseri em Pádua, quem completou o trabalho escrito faltando acrescentar as gravuras que ilustrariam o texto. O tratado, conhecido pelo nome De humani corporis fabrica libri decem, viria a ser publicado em dois volumes, em Veneza, pelo Evangelista Deuchino em 1627, já pela mão do discípulo de Van den Spiegel, o anatomista Daniel

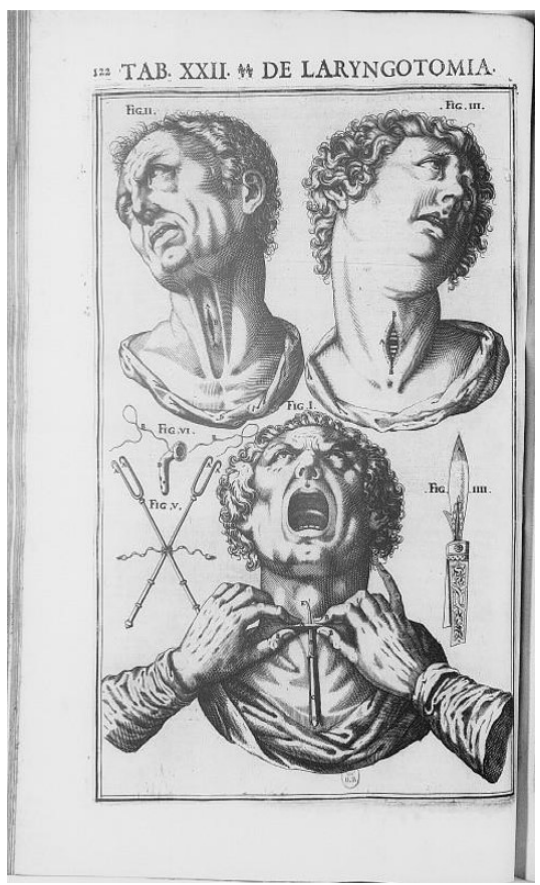

Fig. 4 - Placentinus Julius Casserius, De vocis auditusque organis historia anatomica....tractatibus duobus explicata ac variis iconibus aere excusis illustrata.

V. Baldinus Ferrara, $1600-1601$, fl. 122, Tab XXII

(Rare Books Full Bibliographic Record: Link to Wellcome Library Catalogue) 


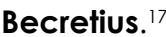

As gravuras que ilustram o tratado (no segundo volume da obra) foram atribuídas a Casseri, mas sabemos que as pranchas originais ter-se-ão perdido, e que Becretius contratou o desenhador bolonhês Odoardo Fialetti ${ }^{18}$ que, de resto, havia já contactado com este trabalho, para completar as imagens que viriam a ser gravadas por Francesco Valesio. Desta forma, o álbum anatómico de gravuras de Fialetti, Tabulae Anatomicae, foi integrado no tratado de Casseri e van den Spiegel em 1627.

Por todos estes motivos, a obra De humani corporis fabrica libri decem possui uma fortuna muito complexa: nasceu com Casseri e com van Spiegel, foi trabalhada por Becretius, e nela se incluíram os desenhos de Fialetti.

Odoardo Fialetti (1573 - 1638) é um artista ainda muito desconhecido. Provável discípulo de Tintoretto, este pintor e desenhador ficou conhecido, essencialmente, através dos inúmeros desenhos que concebeu, subordinados aos mais variados assuntos que vão desde os temários religioso e mitológico, passando por mapas, retratos, ilustrações de textos literários, entre tantos outros. O seu interesse pela gravura e pelos livros, entendendo-os correctamente como meios eficazes de circulação de ideias, de conhecimento e de formas, bem como o seu fascínio pela anatomia, fizeram-no trabalhar no âmbito do desenho anatómico em associação com o trabalho científico que então se desenvolvia de forma incandescente em Itália.

Os desenhos anatómicos de Odoardo Fialetti, e que se exibem na obra de Casseri e de Van den Spiegel, consubstanciam obras de arte de grande qualidade estética, influenciando densamente os trabalhos que artistas posteriores dedicaram ao mesmo assunto. O autor colocou os corpos, ou os membros dos corpos, ou as ossadas, articulações, órgãos e músculos humanos em poses sensuais contra fundos naturais (nos quais podemos ver montanhas, arvoredo, rios, flores e casario), ou de paisagens que nos fazem lembrar o ambiente estético da pintura da época (fig. 5). Na realidade, estes são desenhos de corpos dissecados, ou de cadáveres que, pela sua animação, beleza e voluptuosidade, e conjugados com as fórmulas artísticas de exposição, não nos oferecem imagens científicas tout court, mas obras de arte de elevada qualidade ao serviço da ciência. Os desenhos de Fialetti revelam um profundo conhecimento do corpo humano (porque o artista emparceira com o trabalho teórico e prático desenvolvido pelos anatomistas), as suas intenções de veiculação informativa para outros círculos de interesse, fundamentalmente artísticos e, especialmente, o seu fascínio pelo naturalismo e pelas formas corporais que trata com densa delicadeza, numa clara intenção de desenhar o Belo e a poesia que o corpo expele.

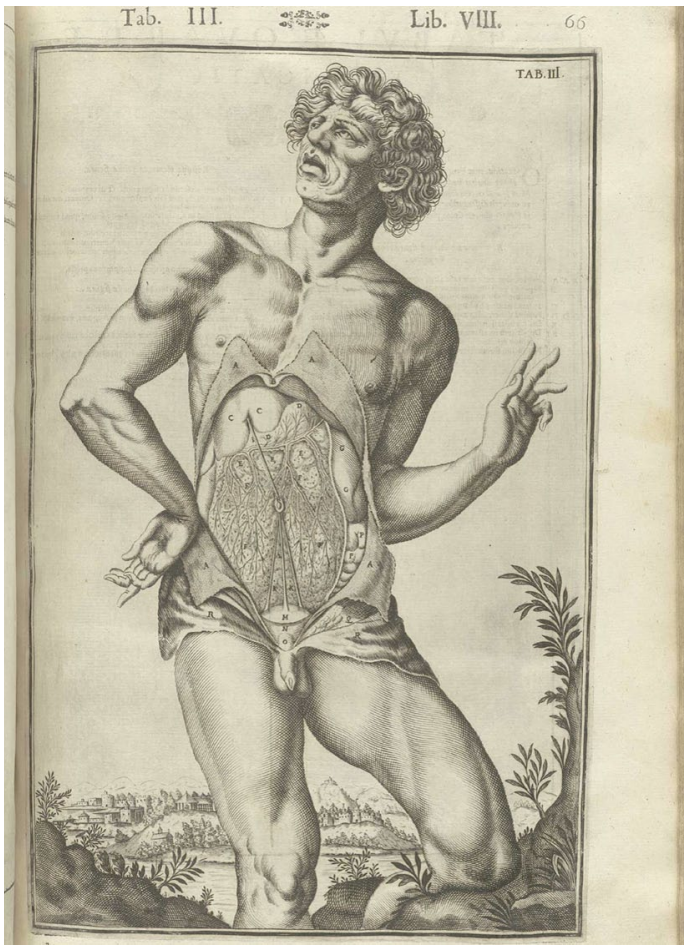

Fig.5 - Adriaan van Spiegel, Giulio Casseri

(desenho de Odoardo Fialetti),

De humani corporis fabrica libri decem. Veneza:

Evangelista Deuchino, 1627, Tauola III, Livro VIII, fl. 65. 


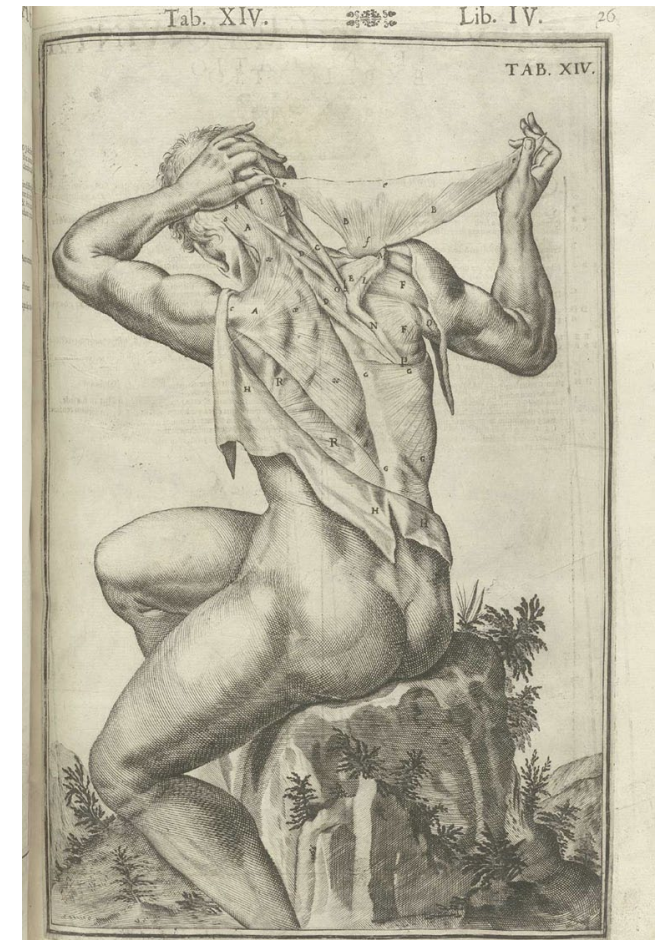

Fig.6 - Adriaan van Spiegel, Giulio Casseri

(desenho de Odoardo Fialetti ),

De humani corporis fabrica libri decem. Veneza:

Evangelista Deuchino, 1627, Tauola XIV Livro IV, fl. 26.

Em conclusão, todos os álbuns de anatomia aqui referidos de forma breve e sucinta (escolhidos de entre tantos outros que ficaram por nomear) ${ }^{19}$ acompanham o espírito do Renascimento, e a sua própria evolução, como uma época profundamente empenhada em desvendar a natureza e o homem que se assume como uma entidade natural. Anatomistas e artistas plásticos trabalharam numa parceria frutífera, estabelecendo como metas principais a difusão do conhecimento anatómico aliado sempre ao saber fisiológico, determinante para o avanço do saber médico. A difusão do objecto livro, consentiu uma rápida transferência de conhecimento, agora ao alcance de cientistas e de artistas que, por sua vez, e facilitados pelas ilustrações que estes álbuns incluíam, encontraram importantes fontes de meditação e de influência que thes garantiram um crescente domínio sobre a anatomia do corpo humano.

Durante os anos que medeiam os séculos $\mathrm{XV}$ e XVI a natureza é entendida como uma criação que o artista imita recorrendo à ciência. A par desta circunstância, o artista procurava, através da pesquisa que empreendia e dos avanços técnicos de que dispunha, representar o natural, o verosímil e o Belo, antes de quaisquer outras causas. Aliado a estes fenómenos, o ambiente filosófico neoplatónico e neo-aristotélico, que se estendeu desde a Idade Média, constituiu-se como um leito de ideias convenientemente acolhido pela intelectualidade, da qual passam a fazer parte alguns artistas. $O$ amor pelo homem, pela natureza que se revela no seu esplendor e pelo conhecimento e procedimentos metodológicos e cientíícos greco-latinos, fazem com que o artista, na sua prática, reproduza o que a natureza lhe oferece como fonte inesgotável de motivos, servindo-se de um conjunto vastíssimo de informações que transforma e redefine no sentido de recriar o encantamento do mundo.

Recuperando-se, durante os séculos $X V$ e $X V I$, a ideia do humanismo onzecentista que descobria no homem uma realidade vivente e individual, e uma fonte de criação e de invenção, refirmando-se a ideia de que o homem é a medida de todas as coisas (das visíveis e das invisíveis), os artistas do Renascimento encabeçam um movimento totalmente novo de deslumbramento pelo corpo humano. É neste ambiente de epifania que surge o tratado de Albrecht Dürer, Hierinn sind begriffen vier bücher von menschlicher Proportion..$^{20}$ Nesta obra, o artista revela os seus estudos sobre as proporções do corpo humano, pois que o mediu matematicamente, atribuindo-lhe comensuração e volumetria, desta feita sem as clássicas preocupações com o Belo, ou com a beleza corporal genérica. Intenta o artista sistematizar as medidas que realizou dos vários tipos de corpos reais, comuns e individuais (também com as suas deformidades de tamanho e de largura), ou dos corpos que nos habituamos a ver $e$ 
que habitam connosco, ao invés dos corpos gerais, aqueles que sobrevivem dos ideais de harmonia. Este tratado inteiramente realizado por um artista, abriu as portas às ciências antropométricas contemporâneas (fig. 7) e comprova o que temos vindo a tentar sistematizar: as inquietações com o conhecimento do corpo humano

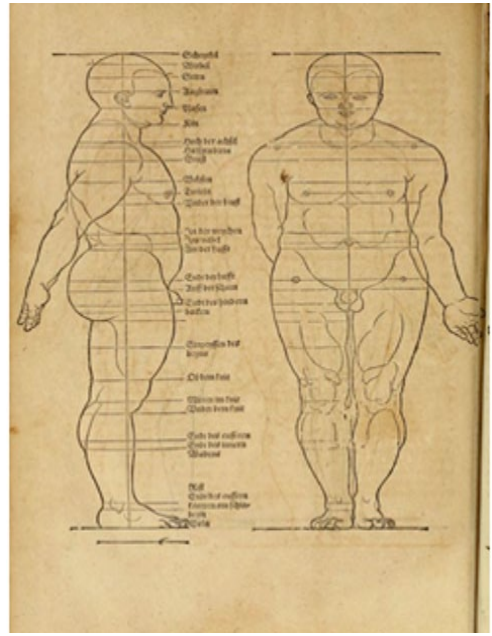

Fig.7 - Albrecht Dürer, Hierinn sind begriffen vier bücher von menschlicher Proportion. Willibald Pirckheimer. Nuremberg: Hieronymus Andreae Formschneider for Dürer's widow, 31 October 1528.

Em linha: http://archive.org/stream/ hierinnsindbegri00dure\#page/108/mode/2up

pertencem a cientistas e a artistas.

Se o De Fabrica, de Vesalius, conheceu a sua primeira edição no início dos anos quarenta do século de Quinhentos, os artistas, que tal como os físicos e cirurgiões pesquisavam sobre com o corpo, utilizavam as suas próprias ferramentas de trabalho para o reconhecer e representar fielmente. Foi com esse mesmo objectivo que Leonardo da Vinci e Miguel Ângelo (entre tantos outros artistas) realizaram as suas próprias dissecações, anos antes dos mais consequentes álbuns de anatomia ilustrados terem vindo a lume.

Os escultores do século XVI não teriam representado o corpo sem o contemporâneo desenvolvimento da ciência anatómica. E se os gravados de artistas desde Martin Schongaver, passando por Dürer, Lucas de Lyden, Veit Stoß, até Cornelis Cort, Hieronymus Wierix, entre tantos outros que nos escusamos de elencar, marcaram o imaginário dos escultores na interpretação dos seus temas e na reprodução dos tantos motivos decorativos, os álbuns de anatomia cumpriram outra missão, tão ou mais importante, presa com a aquisição do saber necessário para a adequada realização das suas obras que se comprometiam directamente com o mundo e com os homens que nele habitam.

Haverá, então, um corpo para a ldade Moderna? Certamente que sim, se comparado com as configurações imediatamente anteriores. $O$ corpo da Idade Moderna é, afinal, o corpo real, densamente estudado e representado por cientistas e desenhadores que, a par, deram a conhecer as vísceras dessa realidade até então parcialmente reconhecida. A representação do corpo durante a ldade Moderna espelha o que o homem observa e espelha o que o homem quer ver, desabrigando os laivos de concupiscência que até então lhe eram proibidos. Os desenhos anatómicos que aqui recordámos não retratam o corpo morto, mas o corpo animado, mesmo que sem pele e com as entranhas à vista, o corpo belo e harmónico com que a natureza dotou o homem para, por sua vez, dotar o mundo. Também por este motivo, a representação do corpo na ldade Moderna espelha a realidade e a utopia, ou o que é e o que deveria ser, sempre de acordo com a sua funcionalidade e especificidade de material vivo e prenhemente disposto à observação e ao estudo para ulterior exposição, como elemento único que alia a beleza e a tecnologia. O corpo representado durante os séculos em aferição é, justamente, esse corpo feito dos seus pedaços, das suas mãos e pés, das suas bocas e olhos, do seu estômago e rins, animado pelos gestos de quem reentra no mundo com mais certezas, e expressa a dor, e expressa a glória, e expressa a vida que lhe entrou para nele se fixar e sair, e expressa o mundo natural ao qual pertence e no qual age.

E porque não podemos fechar 
este workshop sem uma referência importantíssima a Francisco de Holanda que reflectiu sobre os corpos e a sua representação durante o século XVI, recuperemos o que ele nos legou quando escreveu: «E lembre-vos que a figura que ao natural tirardes em retrato para fazerdes de fantasia, que debaixo do vestido há-de ter carne, e debaixo da carne metidos os ossos porque aqui cometem grandes ignorâncias os ignorantes». ${ }^{21}$

\section{Notas}

(1) Cf.: VASARI, Giorgio, Las vidas de los más excelentes aquitectos, pintores y escultores italianos desde Cimabue a nuestros tempos (Antología) Estudio, selección y traducción de María Ménez Baiges y Juan María Montijano García. Madrid: Alianza Editorial, 2004, p. 94. (2) VASARI, Giorgio, Las vidas de los más excelentes aquitectos, pintores y escultores italianos desde Cimabue a nuestros tempos (Antología) [...], pp. 107 e 108.

(3) LE GOFF, Jacques, Os intelectuais da ldade Média. Lisboa: Gravida, 1990, p. 71.

(4) AQUINO, Tomás de, Expositio super Dionysium de divinis nominibus, 362. [c. 1268].

(5) Sobre este ainda enigmático autor e os desenhos dos seus mapas humanos veja-se WITTINGTON, Karl, «Experimenting with Opicinus de Canistris (1296 c. - 1354)1), GESTA. The University of Chicago Press, vol. 51, n. ${ }^{\circ}$ 2, 2012, pp. 147 a 173. Em linha: https://www.academia.edu/3200619/ Experimenting_with_Opicinus_de_Canistris_1296ca.1354_ [última leitura em Dezembro de 2012]. (6) Avignon, França. 1335-50. Biblioteca Apostólica Vaticana. Cidade do Vaticano, Pal. Lat. 1993.

(7) Opicinus de Canistris. Diagrama com os símbolos do zodíaco. Avignon, França, 133550. Biblioteca Apostólica Vaticana, Cidade do Vaticano, Pal. Lat. 1993.

(8) O Livro foi disponibilizado online pela National Library of Medicine. Em linha: http://archive.nlm. nih.gov/proj/ttp/flash/brunschwig/brunschwig. html [última consulta em Outubro de 2013]. (9) Cf. PRIORESCHI, Plinio, Berengario da Carpi: Renaissace Anatomist. Documento em Linha de um artigo que integraria a o volume VI da História da Medicina que ainda não veio a lume. O autor explica que o artigo deveria publicar-se em: "History of Medicine", Vol. VI, Renaissance Medicine, Omaha, Horatius Press, 2006.
(10) De autoria ainda incerta, na medida em que não podemos certificar que as gravuras tenham sido realizadas por Berengario, ou pelo gravador Hugo da Capri (ou Ugo da Carpi 1455-1523) a quem se atribui a invenção do claro-escuro na gravura (Cf. LANDAU, David e PARSHALL, Peter, The Renaissance Print, 1470-1550. Yale University, 1994). Segundo Vasari: «Hugo de Carpi due el inventor de las planchas de madera, que, com três partes, destacan además el dibujo, las sombras, los médios tonos y las luces.l. Mais à frente, na mesma obra, Vasari acrecenta que: "Ugo da Carpi, inventor de cosas ingeniosas y fantásticas, invento los grabados de madera; por médio de três estampas, com las que se realiza la media tinta, las luces y las sombras, se consigeun imitar losn dibujos sobre papel claroscuro, hermosa e ingeniosa invención que lvego se há praticado mucho.» (VASARI, Giorgio, Las vidas de los más excelentes aquitectos, pintores y escultores italianos desde Cimabue a nuestros tempos (Antología), Estudio, selección y traducción de María Ménez Baiges y Juan María Montijano García. Madrid: Alianza Editorial, 2004, p. 134 e 354 respectivamente).

(11) Cf. De humani corporis fabrica. Em Linha: http://vesalius.northwestern.edu/ [última leitura em 1 de Outubro de 2013].

(12) Para consulta da gravura, cf.: Livraria da Universidade da Virgínia, em linha: http://www. Iva.virginia.gov/public/archivesmonth/2002/ archweek_images/uvahs/uva_vesalius2.htm (13) Jan Stephan van Calgar tinha já colaborado com Vesalius, sem quaisquer sombras de dúvidas, nos desenhos das seis Tabulae Anatomicae, de 1538. Há, todavia, investigação a realizar para confirmar-se a sua directa participação no De Fabrica. Cf.: GUERRA, Francisco, «The identity of the artists involved in Vesalius's Fabrica 1543». Medical History. Cambridge University Press, 1969 January; 13(1): 37-50. em linha: <http:// europepmc.org/articles/PMC 1033893/pdf/ medhist00 140-0048.pdf> [última leitura em Outubro de 2013].

(14) Cf.: DILLON, Anne, Michelangelo and the English martyrs. Farnham: Ashgate Publishing Group, 2012.

(15) O livro encontra-se, em formato digital, na Biblioteca Nacional de Espanha, em: http://bdh-rd.bne.es/viewer.vm?id=0000050806 Na Biblioteca Nacional Digital [res-3353-v], em: http://purl.pt/15007/3/\#/0.

(16) Cf.: ZIMMERMAN, Leo M. e VEITH, Ilza, Great ideas in the history of surgery. San Francisco: 
Norman Pub., 1993.

(17) Observing the World through Images: Diagrams and Figures in the Early-Modern Arts and Sciences. Edição de Christoph Luthy e Isla Fay. Leiden: Brill, 2013.

(18) Fialetti era irmão de Tiberio, um conhecido anatomista, doutor em medicina e filosofia, de Pádua. Cf. WALTERS, Laura M., Odoardo Fialetti (1573-c. 1638): the interrelation of Venetian art and anatomy, and his importance in England, 2009. Tese de Doutoramento. St Andrews Digital Research Repositoryat. in:

https://research-repository.st-andrews.ac.uk/ (19) Tais como o livro de anatomia ilustrado de Johannes de Ketham, Fasciculus Medicinae. Venezia: Gregori, 1493 [Em linha, facultado pela National Library of Medicine: http://archive. nlm.nih.gov/proj/ttp/flash/ketham/ketham.html (última leitura em Dezembro de 2013)], para o século XV, ou os trabalhos do físico inglês William Harvey (1578-1657)

(20) DÜRER, Albrecht, Hierinn sind begriffen vier bücher von menschlicher Proportion. Willibald Pirckheimer. Nuremberg: Hieronymus Andreae Formschneider for Dürer's widow, 31 October 1528. Em linha: http://archive.org/stream/ hierinnsindbegri00dure\#page/108/mode/2up [última consulta em Outubro de 2013].

(21) HOLANDA, Francisco de, Do Tirar Polo Natural. Lisboa: Livros Horizonte, 1984, p. 36.

\section{Bibliografia}

Dillon, A. (2012), Michelangelo and the English martyrs. Farnham: Ashgate Publishing Group.

Dürer, A. (1528), Hierinn sind begriffen vier bücher von menschlicher Proportion. Willibald Pirckheimer. Nuremberg: Hieronymus Andreae Formschneider for Dürer's widow, 31 October.

Guerra, F. (1969), «The identity of the artists involved in Vesalius's Fabrica 1543». Medical History. Cambridge University Press; 13(1): 37-50.

Holanda, F. de (1984), Do Tirar Polo Natural. Lisboa: Livros Horizonte.

Landau, D. e Parshall, P. (1994), The Renaissance Print, 1470-1550. Yale University.

Le Goff, J. (1990), Os intelectuais da Idade Média. Lisboa: Gradiva.

Vasari, G. (2004), Las vidas de los más excelentes aquitectos, pintores y escultores italianos desde Cimabue a nuestros tempos
(Antología) Estudio, selección y traducción de María Ménez Baiges y Juan María Montijano García. Madrid: Alianza Editorial.

Walters, L. M. (2009), Odoardo Fialetti (1573c. 1638): the interrelation of Venetian art and anatomy, and his importance in England. Scotland, UK: University of St. Andrews.

Wittington, K. (2012), «Experimenting with Opicinus de Canistris (1296 C. - 1354)», GESTA. The University of Chicago Press, vol. 51, n. ${ }^{\circ} 2$.

Zimmerman, L. M. e Veith, I. (1993), Great ideas in the history of surgery. San Francisco: Norman Publications. 